\title{
Research on the Stability of Circular Economy Enterprise Alliance Based on Redistribution of Benefits
}

\author{
Shaozeng DONG, Xiaoling WANG* \\ Harbin University of Science and Technology \\ dongshaozeng@163.com
}

\begin{abstract}
Keywords: Circular economy, enterprise alliance, stability, benefit distribution
Abstract. Circular economy enterprise alliance is an effective way for enterprises to achieve recycling economy development model, and is of great significance to the development of the national economy as a whole. This paper aims to explore how to improve the operational efficiency of the enterprise alliance and reduce the risk of dissolution of the Union, from the angle of the redistribution of the interests of the enterprise alliance, integrating the rate of the alliance members' actual contribution to the enterprise alliance. Additionally, by constructing the benefit distribution model of the alliance members, this paper studies the dynamic stability of the circular economy enterprise alliances.
\end{abstract}

\section{Intrinsic link between circular economy and enterprise alliance}

\section{Enterprise alliance is the important carrier of developing circular economy}

Circular economy is a new economic development model which comprehensively considers the economic, social and environmental benefits. Compared with traditional economy, what is particular about circular economy lies in that traditional economy is a linear economy, one-way flow of goods consisting of "resources - products - pollution emissions"; Circular economy is an advocate of establishing the economy development model based on constantly recycled material whose operating mode is "Resource - Products - Pollutants"[1]. In the circular economy, enterprises are in pursuit of comprehensive benefits and aim to find a path to sustainable development by improving the competitive power and environmental adaptability. A single enterprise is restricted by firm size, resource acquisition and technology in seeking the development model of circular economy. The emergence of enterprise alliance solved the problem of resource constraints, improved the operation efficiency of enterprises, and enhanced the competitiveness of enterprises. As an important carrier of the development of circular economy, enterprise alliance ensured the implementation of corporate seeking circular economy mode.

\section{Circular economy is the fundamental guarantee for the sustainable development of enterprise alliance}

Enterprise alliance's presence does not increase the effectiveness of the entire enterprise system, but can reduce the costs in the process of single enterprise's resource acquisition and technology development, improve the efficiency of enterprise alliance symbiotic chain and increase enterprise alliance performance, through mutual cooperation among alliance members. The enterprise alliance redistributes the alliance benefits to maximize the benefits of alliance members. Circular economy is a new economic model of sustainable development and the foundation of enterprise's sustainable development, presupposes the existence of corporate alliances, and ensures the long history of the interests of enterprise alliance and its members .

Enterprise alliance's sustainable development and sustainable revenue coincide with the ecological requirements of economic development in circular economy model, the combination of which built a circular economy enterprise alliance shown in Fig.1. Under the guidance of the circular economy development model, enterprise alliance, by ways such as the process upgrading, product upgrading, functional upgrading and value chain upgrading, enhances their competitiveness and 
environmental adaptability, and increases their overall income, in order to realize the circular economy development model.

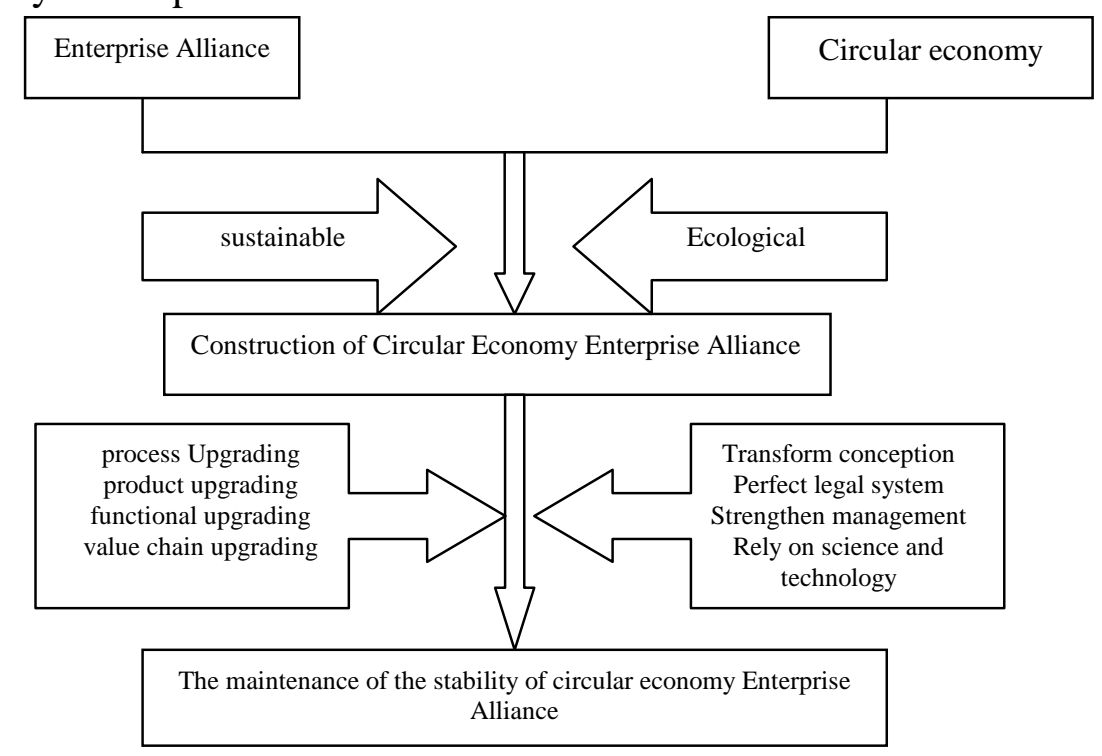

Fig.1 Diagram of Enterprise Alliance and Circular Economy

\section{Connotation of the stability of circular economy enterprise alliance}

The circular economy enterprise alliance is relatively stable or instable. In constant interaction, the alliance members seek the best bonding point to achieve revenue maximization of enterprise alliance and its members. In a dynamic environment, the stability of the strategic alliance, in essence, is a dynamic optimization and improvement of the partnership within strategic alliance in the process of coordinating conflicts and disputes [2]. Enterprise Alliance is a symbiotic system, which is in a dynamic and relatively stable state. Any change of a factor will cause changes of the entire system state. Therefore, alliance symbiotic energy distribution, symbiotic interface selection, symbiosis model changes and changes in the symbiotic environment will cause changes in the alliance symbiotic system[3]. In fact, enterprises establish strategic alliances for the sake of some kind of dependence on alliance partners; alliance has been able to keep in a certain state for the sake of being inseparable from each other. This dependence is an important prerequisite for the establishment and maintenance of alliance[4]. For alliance stability, many scholars have expressed their views: Inkpen\&Beamish hold the belief that alliance instability refers to the unintended change or dissolution from the perspective of one or more partners; Jiang et al. think that alliance termination doesn't mean instability; Xu Libo and Shi Jianjun believe that alliance is stable as long as there is no big change or only intended change in the alliance. In circular economy, enterprise alliance is dynamic, whose stability is actually a dynamic optimization and improvement in the process of alliance members' coordinating conflicts and disputes in order to ensure the sustainable benefits of alliance and its members.

In circular economy, the stability of enterprise alliance is a complicated dynamic process, and is a basic way for enterprise alliance and its members to pursue the sustainable development and sustainable benefits. In circular economy, enterprises build alliance by all means and its fundamental purpose is to achieve the maximization of self-interest. Because of different considerations of alliance members, the circular economy enterprise alliance will encounter a variety of risks in the running process. Among which, what is particularly prominent is actual risk of the coalition supply chain inefficiencies and even the disintegration due to the uneven distribution of alliance benefits [5]. Therefore, to study the stability of enterprise alliance from the perspective of from a redistribution of circular economy enterprise alliance benefits has more practical significance. The stability of circular economy Enterprise Alliance can be achieved and maintained by ensuring the maximization of alliance members' own interests. 


\section{The design of circular economy alliance based on a redistribution of benefits}

In circular economy, an important factor that influences the stability of enterprise alliance is the redistribution of enterprise alliance benefits. A fair distribution program of enterprise alliance benefits can balance the benefits relationship between alliance members and increase the alliance members' initiative in maintaining alliance stability. Therefore, how to seek a fair distribution of alliance member benefits is the key to maintain a stable alliance chain and the important way to enhance the stability of circular economy enterprise alliance.

In circular economy, $N=\{1,2, \ldots, \mathrm{n}\}$ is denoted as the collection of enterprise entities, $y=\left\{y_{1}, y_{2}, \ldots, y_{n}\right\}$ is denoted as enterprise income, Nonempty subset of " $\mathrm{N}$ ", $\mathrm{S}=(1,2, \ldots, \mathrm{S})(\mathrm{S} \subset \mathrm{N})$ is denoted as circular economy enterprise alliance. The meaning of the characteristic function is: In circular economy, enterprise alliance achieves the maximization of enterprise alliance benefits by coordinating the various resources of alliance members. When the benefits of circular economy enterprise alliance are maximized, the benefits gained by the alliance member " $\mathrm{i}$ ” is denoted as “ $y_{i}$ ". In circular economy, enterprise alliance should meet the following rational conditions:

(1) Individual rational condition: $y_{i}>f\left(y_{i}\right)$

$f\left(y_{i}\right)$ represents the benefits gained when the enterprise alliance in circular economy has only one enterprise " $i$ "(namely enterprise" $i$ "does not participate in enterprise alliance). Enterprise's participation in circular economy enterprise alliance is to seek the development model of circular economy, whose fundamental purpose is to gain more benefits. Therefore, individual rational condition requires that the benefits gained by enterprise entities from the distribution of circular economy enterprise alliance benefits be greater than that under non-aligned circumstances.

(2) Overall rational condition: $\sum_{i=1}^{n} y_{i}=f(\mathrm{~N})$

As part of circular economy enterprise system, the construction of circular economy enterprise alliance is through the effective coordination of the relationship between alliance members, thus to form enterprise alliance unity, enhancing enterprise alliance's competitiveness in circular economy enterprise systems and increasing the benefits gained from the system.

(3) Alliance rational condition: $\sum_{i=1}^{s} y_{i}>f(\mathrm{~S}), \forall S \subset N$ 且 $\mathrm{s}>1$

Circular economy enterprise system as a whole does not increase the benefits. If the enterprise entities want to get more benefits, they have to improve their competitiveness in enterprise system. The construction of circular economy enterprise alliance effectively coordinates the mutual relationship between alliance members, improves resource utilization, enhances the competitiveness of enterprise alliance and its members, and gets more benefits from the entire circular economy enterprise system.

In the circular economy enterprise alliance, the existence of front end enterprises not only ensure the stable cis-after production, but also maintain the stability of the entire enterprise symbiosis chain and reduce the risk of its disintegration. In addition to gaining benefits both by operating outside the enterprise alliance system and by providing the corresponding cyclic compounds for symbiosis chain, the front end enterprises have also made a great contribution to maintaining the dynamic stability of enterprise alliance. Therefore, as for the distribution of benefits of circular economy enterprise alliance, the contributions made by front end enterprises to the entire enterprise alliance symbiosis chain should be followed with interest.

The redistribution of benefits of enterprise alliance in circular economy should fully consider the alliance members' contribution on economic, social and environmental benefits, and be carried out based on the principle of comprehensiveness and fairness. If ${ }^{c_{i}}$ represents alliance members' 
comprehensive contribution to the entire alliance, the benefits of alliance members get are $y_{i}=y_{i}^{\prime}+y_{i}^{\prime \prime}$, $y_{i}$ represents the benefits gained by the alliance members through independent foreign operation, and $y_{i}{ }^{\prime \prime}$ represents the distribution of benefits gained through the comprehensive contribution made by alliance members to circular economy enterprise alliance. The redistribution of enterprise alliance benefits in circular economy should follow the principle: $\frac{y_{1}{ }^{\prime \prime}}{c_{1}}=\frac{y_{2}{ }^{\prime \prime}}{c_{2}}=\ldots=\frac{y_{i}{ }^{\prime \prime}}{c_{i}}$

In the circular economy enterprise alliance carrying out the redistribution of benefits, to maximize their own benefits, the alliance members should on the one hand actively improve their independent operational capacity and the access to ${ }^{y_{i}}$; on the other hand continuously make contributions to circular economy enterprise alliance, in order to gain more benefits from alliance redistribution. In the system of circular economy enterprise alliance, $\mathrm{y}_{i}^{\prime \prime}>>y_{i}^{\prime}$, so the benefits to be gained by circular economy enterprise alliance members will focus mainly on the redistribution of enterprise alliance benefits.

To maintain the stability of enterprise alliance, circular economy enterprise alliance must be able to bring new benefits distribution to alliance members; gaining the new benefits of enterprise alliance depends on the alliance members' trust on alliance and their contributions to the alliance. The relationship of circular economy enterprise alliance and alliance members is a mutual exchange based on trust. The stable alliance can bring about sustainable benefits distribution for alliance members, and the alliance members can make more contributions to the stability of enterprise alliance after they get corresponding benefits from alliance.

\section{Conclusion}

Circular Economy Enterprise Alliance is a symbiotic alliance, and alliance members seek to maximize the benefits. The irrational distribution of benefits has a great impact on the operational efficiency of the enterprise alliance and increases the risk of the disintegration of circular economy enterprise alliance. In this paper, the stability of circular economy enterprise alliance is discussed from the perspective of benefits distribution of circular economy enterprise alliance, through building benefits distribution models, and through alliance members' actual contributions to enterprise alliance in both improving alliance competitiveness and maintaining alliance stability. The default of this paper is the lack of effective measure of alliance members' actual contribution, which needs further study.

\section{REFERENCES}

[1]SHEN Xiangyi. Circular Economy Strategy for SME development[J]. China New Technology and New Products, 2011 (12) : 195.

[2]XU Libo. Perspective Based on Dynamic Stability Union[J]. Modern Management Science, 2011 (12) : 195.

[3]FENG Lumin, Based on Symbiosis Theory Study on Stability of Industrial Technology Innovation Alliance[D]. Nanjing: Nanjing University of Posts and Telecommunications, 2012.

[4]XU Libo,SHI Jianjun,WU Qiong. Stability of Strategic Alliance Research[J]. Xuehai,2011 (5) : 75-78.

[5]CAI Shaohong,LU Lin. Recycling of industrial clusters symbiotic alliance stability design based on the distribution of benefits Perspective [J]. Technology \& Management Research, 2011 (3) : 3-7. 